\title{
Determinação de hemograma, bioquímica sérica e pesquisa de hemoparasitas em quatis (Nasua nasua) em condições de cativeiro no Estado do Rio de Janeiro
}

\section{Blood values, clinical chemistry and hemoparasites research in captive coatimundi (Nasua nasua) from Rio de Janeiro}

\author{
Renata Rocha Rodrigues ${ }^{1}$, Carmen Helena de Carvalho Vasconcellos², Nádia Regina Pereira Almosny ${ }^{3}$, \\ Marcílio Dias do Nascimento ${ }^{4}$
}

\section{Resumo}

Onze quatis (Nasua nasua), de ambos o sexos e idades variadas, clinicamente sadios, mantidos em cativeiro no Horto Botânico de Niterói e no Zoológico Municipal de Volta Redonda, foram utilizados para colheita de amostras sangüíneas, visando a realização de exames hematológicos. Estes exames consistiram na determinação de hemograma, dosagens séricas de glicose, uréia, creatinina, proteinas totais, albumina, globulinas, aspartato-aminotransferase (AST), alanina-aminotransferase (ALT) e colesterol, além de pesquisa de hemoparasitas. As amostras foram obtidas por punção das veias cefálica e/ou femural, e processadas no Laboratório de Patologia Clínica da Faculdade de Veterinária da Universidade Federal Fluminense. Os valores médios encontrados foram: hemácias $=5,5 \times 10^{6} / \mathrm{mm}^{3}$; volume globular $=33,5 \%$; hemoglobina $=11 \mathrm{~g} \%$; volume globular médio $=61,9 \mathrm{fl}$; concentração de hemoglobina globular média $=32,1 \%$; leucócitos $=8950 / \mathrm{mm}^{3} ;$ basófilos $=0 \%$; eosinófilos $=10 \%$; bastões $=0 \%$; segmentados $=56 \%$; linfócitos $=30 \%$; monócitos $=3 \%$; proteínas totais $=9,4$ $\mathrm{g} \%$; albumina $=3,8 \mathrm{~g} \%$; globulinas $=5,6 \mathrm{~g} \% ; \mathrm{ALT}=31,1$ UI; AST $=47 \mathrm{UI}$; glicose $=110 \mathrm{mg} / \mathrm{dl}$; uréia $=25 \mathrm{mg} / \mathrm{dl}$; creatinina $=0,7 \mathrm{mg} / \mathrm{dl}$; colesterol $=288 \mathrm{mg} / \mathrm{dl}$. Não foram encontradas hemoparasitas nas amostras examinadas. Concluiu-se que estes valores são semelhantes aos relatados na literatura para canídeos domésticos e outros procionídeos, como o guaxinim (Procyon sp.). Não houve influência significativa nos valores obtidos com diferentes métodos de contenção.

Palavras chaves: exames hematológicos; Nasua nasua; quatis; Rio de Janeiro

\section{Introdução}

O quati é um mamífero, da Ordem Carnivora, Família Procyonidae, habitante das matas do Continente Americano, mesmo em áreas próximas a cidades, estando representado no Brasil pela espécie Nasua nasua. É um animal onívoro, que se reproduz com facilidade, sendo encontrado em quase todos os zoológicos do país. Quando capturado jovem, se torna dócil, o que permite que seja, muitas vezes criado em residências, como animal de estimação (Wallach e Boever, 1983; Meheren, 1986).

Segundo Wallach e Boever (1983), os procionídeos são altamente suscetíveis a várias doenças infecciosas, patogênicas ao homem e aos animais domésticos, apresentando quase todas as moléstias encontradas no cão e no gato domésticos. Por isso, deve-se estabelecer um programa de medicina preventiva que vise a proteção do indivíduo e de outras espécies em contato próximo.

Os exames hematológicos são de grande auxílio ao clínico veterinário como recurso diagnóstico, determinação de prognóstico ou assessoramento terapêutico (Schalm et al., 1975).

O objetivo deste trabalho foi fornecer valores hematológicos que possam servir de base para futuras avaliações, uma vez que, na bibliografia consultada, o único relato a este respeito foi o de Soifer, em 1977.

\section{Material e Métodos}

As amostras de sangue foram colhidas de 11 quatis (4 machos e 7 fêmeas), de idades variadas, clinicamente sadios, mantidos em cativeiro no Horto Botânico de Niterói (animais 1 ao 7) e no Zoológico Municipal de Volta Redonda (animais 8 a 11), através de punção das veias cefálica e/ou femural e separadas em três frascos: o pri- 
Exames hematológicos em quatis • R.R. Rodrigues et al.

meiro contendo anticoagulante derivado do ácido etilenodiaminotetracético (EDTA) ${ }^{1}$; o segundo com fluoreto de potássio ${ }^{2}$ e o terceiro sem anticoagulante, para obtenção do soro.

Um grupo de animais foi contido mecanicamente, com rede de caça e puçá; o outro foi submetido à contenção química, com cloridrato de quetamina ${ }^{3}$, na dosagem de $20 \mathrm{mg} / \mathrm{kg}$ de peso (Wallach e Boever, 1983).

Os exames foram processados no Laboratório de Patologia Clínica da Faculdade de Veterinária da Universidade Federal Fluminense, de acordo com as técnicas citadas a seguir.

Os esfregaços sangüíneos foram confeccionados no momento da colheita, corados pelo método de MayGrünwald/Giemsa ${ }^{4}$ e utilizados para contagem específica de leucócitos e pesquisa de hematozoários.

Com as amostras de sangue em EDTA, realizaramse a hematimetria e a leucometria global, em câmara dupla de Neubauer, com solução diluente segundo Gower e Turk, respectivamente.

A hemoglobina foi determinada por método espectrofotométrico ${ }^{5}$ baseado na formação de cianometahemoglobina ${ }^{6}$.

Os valores do volume globular foram determinados em tubos microcapilares submetidos à centrifugação a $11000 \mathrm{rpm}$, por $5 \mathrm{~min}$.

Para dosagem da glicose foi utilizado o plasma obtido por centrifugação do sangue com fluoreto submetido à reação colorimétrica ${ }^{7}$.

As demais provas bioquímicas foram as dosagens de uréia, creatina, proteínas totais e albumina, aspartatoaminotransferase (AST), alanina-aminotransferase (ALT) e colesterol, realizadas a partir do soro, utilizando-se kits comerciais padronizados ${ }^{8}$. Os valores das globulinas foram estabelecidos por cálculo, subtraindo-se os valores da albumina dos das proteínas totais.

Os valores médios obtidos foram comparados estatisticamente através do teste t de Student $(P<0,05)^{9}$.

\section{Resultados}

Os valores médios obtidos nas amostras examinadas encontram-se relacionados nas Tabelas 1 e 2 .

Nos esfregaços pesquisados não foram encontradas hemoparasitas.
Tabela 1 - Valores médios de hemograma em quatis (Nasua nasua) mantidos em cativeiro

\begin{tabular}{lr}
\hline Hemácias $\left(\times 10^{6} / \mathrm{mm}^{3}\right)$ & 5,5 \\
Volume globular $(\%)$ & 33,5 \\
Hemoglobina $(\mathrm{g} \%)$ & 11 \\
Volume globular médio (fl) & 61,9 \\
Concentração de hemoglobina globular média (\%) & 32,1 \\
Leucócitos (mm $\left.\mathrm{mm}^{3}\right)$ & 8950 \\
Basófilos (\%) & 1 \\
Eosinófilos (\%) & 10 \\
Bastões (\%) & 0 \\
Segmentados (\%) & 56 \\
Linfócitos (\%) & 30 \\
Monócitos (\%) & 3 \\
\hline
\end{tabular}

Tabela 2 - Valores médios de bioquímic̣a sérica em quatis (Nasua nasua) mantidos em cativeiro

\begin{tabular}{lc}
\hline Proteínas totais (g\%) & 9,4 \\
Albumina (g\%) & 3,8 \\
Globulinas (g\%) & 5,6 \\
Relação A/G & 0,67 \\
Aspartato-aminotransferase (UI) & 47 \\
Alanina-aminotransferase (UI) & 31,1 \\
Glicose (mg/dl) & 110 \\
Uréia (mg/dl) & 25 \\
Creatina (mg/dl) & 0,7 \\
Colesterol (mg/dl) & 288 \\
\hline
\end{tabular}

As Tabelas 3 e 4 apresentam valores médios de animais machos e fêmeas e as Tabelas 5 e 6 de animais sedados e não sedados

Tabela 3 - Valores médios de hemograma em quatis (Nasua nasua) machos e fêmeas mantidos em cativeiro

\begin{tabular}{lcc}
\hline & Machos & Fêmeas \\
\hline Hemácias $\left(\times 10^{6} / \mathrm{mm}^{3}\right)$ & 7,1 & 4,0 \\
Volume globular $\%$ ) & 39 & 29,8 \\
Hemoglobina $(\mathrm{g} \%)$ & 13,7 & 9,7 \\
Volume globular médio (fl) & 61 & 62,8 \\
Conc. hemoglobina glob. média (\%) & 31,9 & 32,1 \\
Leucócitos (mm ${ }^{3}$ ) & 12475 & 6600 \\
Basófilos (\%) & 1 & 0 \\
Eosinófilos (\%) & 8 & 14 \\
Bastões (\%) & 0 & 0 \\
Segmentados (\%) & 55 & 56 \\
Linfócitos (\%) & 33 & 27 \\
Monócitos (\%) & 3 & 3 \\
\hline
\end{tabular}

1 Hemstab (cat. 30) - Labtest Sistemas Diagnósticos Ltda. MG, Brasil 2 Glistab (cat. 29) - Labtest

3 Ketalar-Parke-Davis/Aché Laboratórios Farmacêuticos SA, SP, Brasil

4 Soluções Eosina-May-Grünwald e Azur Eosina segundo Giemsa

Reagen - Quimibrás Indústria Químicas SA, RJ, Brasil

5 Espectrofotômetro Bausch-Lomb, modelo 20D

6 Kit para hemoglobina (cat. 43 , com padrão 47) - Labtest

7 Kit para glicose (cat. 28) - Labtest
8 Kit para uréia (cat. 24) - Labtest

Kit para creatinina (cat. 35) - Labtest

Kit para proteínas totais e albumina - Bioclin Química Básica Ltda MG, Brasil.

Kit para transaminase pirúvica (ALT) (cat. 53) - Labtest

Kit para transaminase oxalacética (AST) (cat. 52) - Labtest

Kit para colesterol (cat. 12) - Labtest

9 Sistema SAEG, versão 3.0 - UFV, MG, Brasil 
Tabela 4 - Valores médios de bioquímica sérica em quatis (Nasua nasua) machos e fêmeas mantidos em cativeiro

\begin{tabular}{lcc}
\hline & Machos & Fêmeas \\
\hline Proteínas totais (g\%) & 9,8 & 9,3 \\
Albumina (g\%) & 4 & 3,7 \\
Globulinas (g\%) & 5,8 & 5,6 \\
Relação A/G & 0,7 & 0,7 \\
Aspartato-aminotransferase (UI) & 50,8 & 45,1 \\
Alanina-aminotransferase (UI) & 25,3 & 34 \\
Glicose (mg/dl) & 72,5 & 125 \\
Uréia (mg/dl) & 30 & 24,2 \\
Creatina (mg/dl) & 0,6 & 0,7 \\
Colesterol (mg/dl) & 193 & 383 \\
\hline
\end{tabular}

Tabela 5 - Valores médios de hemograma em quatis (Nasua nasua) sedados e não sedados mantidos em cativeiro

\begin{tabular}{lcc}
\hline & Sedados & Não sedados \\
\hline Hemácias $\left(\times 10^{6} / \mathrm{mm}^{3}\right)$ & 4,9 & 6,8 \\
Volume globular $(\%)$ & 29,8 & 36 \\
Hemoglobina $(\mathrm{g} \%)$ & 9,7 & 12 \\
Volume globular médio (fl) & 61,5 & 62,7 \\
Conc. hemoglobina glob. média (\%) & 32,6 & 31,6 \\
Leucócitos (mm $\left.{ }^{3}\right)$ & 9813 & 8375 \\
Basófilos $(\%)$ & 1 & 1 \\
Eosinófilos $(\%)$ & 12 & 5 \\
Bastões $(\%)$ & 0 & 0 \\
Segmentados (\%) & 55 & 57 \\
Linfócitos (\%) & 29 & 33 \\
Monócitos $(\%)$ & 3 & 4 \\
\hline
\end{tabular}

Tabela 6 - Valores médios de bioquímica sérica em quatis (Nasua nasua) sedados e não sedados mantidos em cativeiro

\begin{tabular}{lcc}
\hline & Sedados & Não sedados \\
\hline Proteínas totais (g\%) & 9,3 & 9,4 \\
Albumina (g\%) & 3,7 & 3,8 \\
Globulinas (g\%) & 5,6 & 5,6 \\
Relação A/G & 0,7 & 0,7 \\
Aspartato-aminotransferase (UI) & 37 & 56,9 \\
Alanina-aminotransferase (UI) & 20,1 & 42,1 \\
Glicose (mg/dl) & 115 & 110 \\
Uréia (mg/dl) & 25,2 & 25,2 \\
CreatinaA (mg/dl) & 0,7 & 0,7 \\
Colesterol (mg/dl) & 198 & 288 \\
\hline
\end{tabular}

\section{Discussão}

Observando os valores obtidos nos animais estudados, que não demonstraram alterações clínicas quando submetidos à colheita das amostras (Tabelas 1,2), podese notar que os valores hematológicos e bioquímicos encontrados se assemelham aos dos carnívoros domésticos e aos dos demais procionídeos, principalmente o guaxinim, de acordo com o que foi proposto por Wallach e Bover (1983).

Os valores do hemograma são semelhantes aos valores relatados por Soifer (1977), excetuando-se a conta- gem total de hemácias e de leucócitos, onde encontramos valores mais baixos. Este resultado, de certa forma o esperado, é devido à diferença de condições de altitude, clima e manejo.

$\mathrm{Na}$ bibliografia consultada, não foram achados dados referentes à bioquímica sérica de quatis, impossibilitando a confrontação dos valores obtidos.

Não foi encontrada variação significativa $(P<0,05)$ entre os resultados dos animais machos e fêmeas (Tabelas 3 e 4), nem entre animais sedados e não sedados (Tabelas 5 e 6). Porém, devem ser realizados estudos mais aprofundados para confirmação desta observação. Ressaltamos, entretanto, que a colheita feita em animais sob sedação com cloridrato de quetamina permitiu um melhor manuseio dos mesmos, com segurança para o animal e para o tratador.

Alguns animais apresentaram valores de AST, ALT e glicose discrepantes das médias encontradas e uma das fêmeas apresentou anemia e eosinofilia, o que sugere parasitose intestinal. A impossibilidade de recaptura dos animais não permitiu a confirmação dessas patologias.

Sugere-se, portanto, a realização de mais pesquisas com animais de nossa fauna, visando suprir a falta de dados disponíveis a este respeito.

\section{Conclusões}

Através dos dados obtidos neste trabalho, pode-se concluir que: (1) os valores hematológicos obtidos não caracterizam variação significativa entre machos e fêmeas e entre animais sedados ou não; (2) a colheita de sangue mostrou-se melhor quando realizada com o animal sedado, por permitir um melhor manejo e evitar o stress; foi o cloridrato de quetamina plenamente satisfatório para essa finalidade; (3) alguns animais apresentaram valores muito afastados da média, entretanto não foi possível relacioná-los com alguma patologia, devido à impossibilidade de recaptura dos mesmos; (4) os valores encontrados mostraram-se semelhantes aos relatados na literatura para canídeos domésticos e outros procionídeos.

\section{Abstract \\ Blood values, clinical chemistry and hemoparasites research in captive coatimundi (Nasua nasua) from Rio de Janeiro}

Eleven coatimundis (Nasua nasua) of both sexes and various ages, clinically healthy, kept in captivity at "Horto Botânico de Niterói" and "Zoológico Municipal de Volta Redonda", were used for collecting of blood samples for hematological examination: hemogram, serum dosages of glucose, urea, creatinine, total protein, albumin, globulins, aspartate aminotranferase (AST), alanine aminotransferase (ALT) and cholesterol, and also hemoparasites research. The samples were obtained by punction of cephalic or femoral veins and were carried out at the Laboratory of 
Clinical Pathology, Faculty of Veterinary, Fluminense Federal University. The following mean values were found: erythrocites $=5,5 \times 10^{6} / \mathrm{mm}^{3} ;$ packed cell volume $=33.5 \%$; hemoglobin $=11 \mathrm{~g} \%$; mean corpuscular volume $=61,9 \mathrm{fl}$; mean corpuscular hemoglobin concentration $=32.1 \%$; leukocytes $=8950 / \mathrm{mm}^{3}$; basophils $=0$; eosinophils $=10 \%$; neutrophils $=56 \%$; lymphocytes $=30 \%$; monocytes $=3 \%$; total protein $=9.4 \mathrm{~g} \%$; albumin $=3.8 \mathrm{~g} \%$; globulins $=5.6$ $\mathrm{g} \%$; AST = $47 \mathrm{UI} ; A L T=31.1 \mathrm{UI} ;$ glucose $=110 \mathrm{mg} / \mathrm{dl}$; urea $=25 \mathrm{mg} / \mathrm{dl}$; creatinine $=0.7 \mathrm{mg} / \mathrm{dl}$; and cholesterol $=$ $288 \mathrm{mg} / \mathrm{dl}$. No hemoparasites were found in the samples. We concluded that these values were similar to those described to domestic Canidae and other Procyonidae, like the racoon Procyon sp. It was not found any meaningful influence in the values obtained when were used different handling methods.
Key words: hematological exams; Nasua nasua; coatimundi; Rio de Janeiro

\section{Referências bibliográficas}

MEHEREN, K. G. Procyonidae. In FOWLER, M. E. Zoo and Wild Animal Medicine. 2 ed. Philadelphia: W. B. Saunders, 1986. 1127 p. Chapter 48: Carnivores (Carnivora), p. 816820.

SCHALM, O. W., JAIN, N. C., CARROL, E. J. Veterinary Hematology. 3 ed. Philadelphia: Lea \& Febiger. 1975. 807 p. Chapter 2: Materials and Methods for the Study of the Blood, p. 15-82.

SOIFER, S. K. Report of the Physiological Normels Committee. Proc. Ann. Meet. Zoo Vet., Michigan, USA, Oct., 1977. p. 120-122.

WALLACH, J. D., BOEVER, W. J. Diseases of Exotic Animals. Philadelphia. W. B. Saunders, 1983. 1159 p. Chapter 6: Procyonidae, p. 465-478. 